Table 5. Deviations from the best planes $(\AA)$

$\begin{array}{lrrr}\mathrm{O}(1) & 0.05 & \mathrm{C}(3) & 0.01 \\ \mathrm{~N}(1) & -0.02 & \mathrm{C}(4) & -0.01 \\ \mathrm{~N}(2) & 0.00 & \mathrm{C}(5) & 0.02 \\ \mathrm{C}(1) & 0.02 & \mathrm{C}(6) & -0.02 \\ \mathrm{C}(2) & -0.01 & \mathrm{C}(7) & 0.01 \\ \mathrm{H}(1) & -0.11 & \mathrm{C}(8) & 0.00 \\ \mathrm{H}(2) & 0.35 & \mathrm{H}(3) & -0.01 \\ & & \mathrm{H}(4) & 0.25 \\ & & \mathrm{H}(5) & -0.59 \\ & & \mathrm{H}(6) & 0.11\end{array}$

The $\mathrm{C}-\mathrm{O}$ bond length $(1.227 \AA)$ indicates typical double bond character and keto form of the compound in the crystalline state. This is confirmed by $\mathrm{H}(1)$ being linked to $N(1)$. The bond lengths in the carbon ring are as expected (mean value $1.386 \AA$ ). In the heterocyclic ring there is a system of conjugated double bonds $\mathrm{O}=\mathrm{C}-\mathrm{C}=\mathrm{N}$. $\mathrm{C}(1)-\mathrm{C}(2)$ shows the characteristic shortening for this system $(1 \cdot 451 \AA) . \mathrm{C}(1)-\mathrm{N}(1)$ is also appropriately shortened $(1 \cdot 345 \AA)$.

The molecules are linked by two strong $(2.774 \AA)$ non-linear $\left(155^{\circ}\right)$ hydrogen bonds. The numbering of atoms, the arrangement of molecules and hydrogen bonds are given in the projection of the structure down $x$ (Fig. 1). It seems that the deviation from coplanarity of the molecule may be caused by the net of strong hydrogen bonds.

\section{References}

International Tables for X-ray Crystallography (1962). Vol. III, pp. 202-203. Birmingham: Kynoch Press.

LEE, J. D. (1974). Loughborough University X-ray System, Loughborough Univ. of Technology.

Ramachandran, G. N. \& Raman, S. (1959). Acta Cryst. $12,957$.

WOJCIECHOWSKI, L. (1972). Private communication.

Acta Cryst. (1976). B32, 2050

\title{
A Comparative Analysis of Structural Parameters Obtained by Diffractometer and Scanning-Densitometer Measurements
}

\author{
By S. NeIDLe, A. Achari AND M. Rabinovitch \\ Department of Biophysics, King's College, 26-29 Drury Lane, London WC2B 5RL, England
}

(Received 11 October 1975; accepted 16 January 1976)

\begin{abstract}
The structure of cytosine monohydrate has been redetermined with reflexion data obtained from automatic digital scanning of Weissenberg films. The previous determination with diffractometer data [McClure \& Craven, Acta Cryst. (1973), B29, 1234-1238] converged to an $R$ of 0.037, with average estimated standard deviations of $0.002 \AA$ and $0.15^{\circ}$ in derived bond lengths and angles. The photographic data set converged to an $R$ of 0.0672 with e.s.d.'s of $0.004-0.005 \AA$ and $0 \cdot 3-0.4^{\circ}$. Normal probability plots showed that the positional (and the derived geometric) parameters were very comparable; the vibrational parameters were rather less so, some systematic error being apparent. The overall conclusion from the study is that the two data sets have given essentially the same positional description of the structure.
\end{abstract}

\section{Introduction}

The past few years have seen the advent of reliable digitizing scanning densitometers, as a means of rapidly estimating reflexion intensities from singlecrystal film data. These instruments have found especial use in the field of protein crystallography (Matthews, Klopfenstein \& Colman, 1972), and have been used for scanning precession, both screened and screenless (Xuong \& Freer, 1971), and oscillation photographs (Arndt, Champness, Phizackerley \& Wonacott, 1973). In general, a sensitive indication of systematic errors in measurement is given by comparison of symmetry-related reflexions, and of reflexions recorded on successive films in a film pack; it has been found that careful scanner measurements caiı compare favourably on this basis with diffractomete ${ }_{i}$ intensity measurement.
The scanner method has also been applied to estimation of Weissenberg-geometry film intensities for smallmolecule crystal structures, albeit on a much more restricted basis, and some structures have been solved with data collected in this manner (for example: Werner, Linnros \& Leijonmarck, 1971; Sussman \& Wodak, 1973; Sjölin, Olsson \& Lindqvist, 1975). A centralized service has recently been set up by the (British) Science Research Council to provide such scanning facilities. As mentioned above, it is straightforward to assess the reliability (and reproducibility) of scanner measurement; our experience, paralleled by that of others (Machin \& Elder, 1975), is that a scanning densitometer can indeed measure intensities from Weissenberg films with an accuracy sometimes approaching diffractometer results, in agreement with experience in the protein field.

Comparison of intensities measured from films, and 
diffractometrically, can in principle, be carried somewhat further, viz by direct comparison of the crystal structures derived from these measurements. This analysis cannot be performed easily on a protein structure, at least with any real degree of precision. However, a highly-refinable small-molecule structure would appear to be a suitable test case. We have chosen the crystal structure of cytosine monohydrate (Fig. 1) for such a test. This well-ordered, small (nine independent non-hydrogen atoms) structure, has been determined by Jeffrey \& Kinoshita (1963) from visual estimation of Weissenberg films, and by McClure \& Craven (1973) (hereafter MC) from four-circle diffractometer measurements. We have concentrated our comparisons on the MC data.

\section{Experimental}

Crystals of cytosine monohydrate were obtained by slow evaporation from aqueous solution. In spite of a difference in morphology compared with the previous report (needles as opposed to plates) cell dimensions were within experimental error. The MC cell dimensions $a=7.783(2), b=9.825(2), c=7.668(2) \AA, \beta=99.57(1)^{\circ}$, were used in our calculations. The space group is $P 2_{1} / c$.

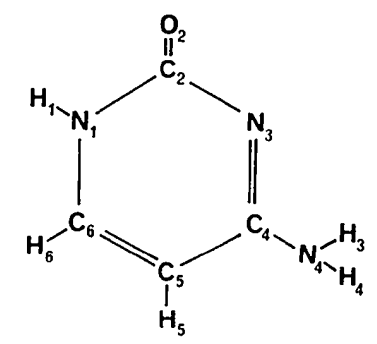

Fig. 1. Cytosine monohydrate.

Intensities were collected by the equi-inclination Weissenberg method, with multi-film packs and $\mathrm{Cu} K \alpha \quad$ Ni-filtered radiation. Layers $0 k l-6 k l$ and $h k 0-h k 5$ were photographed. Particular care was taken $(a)$ to ensure accurate crystal and inclination angle settings, and $(b)$ to standardize film developing and fixing conditions. Films were scanned with an Optronics 1000 scanner. After scaling and merging, 706 unique, observed reflexions were obtained. The average agreement $R_{s}$, between multiple measurements of a reflexion, was $0.078\left(R_{s}=\Sigma\left|\bar{I}-I_{i}\right| / \sum I_{i}\right.$, where $I$ is the mean of the multiple measurements $\left.I_{i}\right)$. An absorption correction was applied.

The diffractometer data collection of MC, also with $\mathrm{Ni}$-filtered $\mathrm{Cu} K \alpha$ radiation, yielded 878 unique reflexions, of which 129 were considered to be unobservably weak as their integrated intensities were less than $1 \cdot 5 \sigma(I)$. Thus 749 reflexions were observed as significant. The rather smaller number of observed reflexions obtained in the present study is due mainly to the known incapacity of the scanner method to measure weak spots that are only slightly (though significantly) above the background level. Indeed visual inspection of the films clearly identified a number of reflexions that the scanner was unable to measure.

Table 1. Results of the least-squares refinement

$\begin{array}{ccc} & \text { This analysis } & \begin{array}{c}\text { McClure \& Craven } \\ (1973)\end{array} \\ \begin{array}{ccc}\text { Number of observed } \\ \text { reflexion intensities }\end{array} & 706 & 749 \\ R=\sum\left|F_{o}\right|-\left|F_{c}\right| / \sum\left|F_{o}\right| & 0.0672 & 0.037 \\ \text { Weighted } R & 0.0694 & 0.045 \\ \text { Weighting scheme } & & \\ w=1 / \sigma^{2}(F) & & \\ \sigma^{2}(F)=A+B F+C F^{2} & 0.3 & 0.185 \\ A & 0 & -0.400 \\ B & 0.00087 & 0.00325 \\ C & \text { Yes } & \text { No }\end{array}$

Table 2. Positional and thermal parameters

(a) Final positional $\left(\times 10^{4}\right)$ and anisotropic thermal $\left(\times 10^{3}\right)$ parameters for the non-hydrogen atoms. Estimated standard deviations are given in parentheses. In each case the values for the present photographic study are given above the MC diffractometer-study values. The MC $U_{l j}$ values have standard deviations of less than $1\left(\times 10^{-3}\right) \AA^{2}$.

$\begin{array}{rrrrrrrrrr} & x & y & z & U_{11} & U_{22} & U_{33} & U_{23} & U_{13} & U_{12} \\ \mathrm{~N}(1) & 845(5) & 68(3) & 2171(5) & 35(2) & 14(1) & 44(2) & 3(1) & 5(2) & -1(1) \\ & 843(2) & 76(1) & 2172(2) & 33 & 21 & 44 & 0 & 7 & 0 \\ \mathrm{C}(2) & 15(5) & 1275(3) & 2394(5) & 34(2) & 18(2) & 34(2) & -2(1) & 1(1) & 1(1) \\ & 16(2) & 1281(1) & 2391(2) & 30 & 26 & 35 & -1 & 5 & 1 \\ \mathrm{O}(2) & -1469(4) & 1243(2) & 2820(4) & 35(2) & 26(1) & 60(2) & 0(1) & 14(1) & 1(1) \\ & -1466(1) & 1239(1) & 2821(2) & 37 & 34 & 61 & 0 & 12 & 0 \\ \mathrm{~N}(3) & 793(4) & 2472(3) & 2108(4) & 34(2) & 19(1) & 41(2) & 0(1) & 1(2) & 2(1) \\ & 795(2) & 2470(1) & 2108(2) & 30 & 23 & 41 & 1 & 6 & 1 \\ \mathrm{C}(4) & 2342(5) & 2442(3) & 1573(5) & 33(2) & 24(2) & 31(2) & 2(1) & 1(2) & 0(1) \\ & 2348(2) & 2445(2) & 1570(2) & 31 & 28 & 34 & 1 & 4 & 0 \\ \mathrm{~N}(4) & 3104(5) & 3624(3) & 1314(5) & 37(2) & 24(2) & 61(3) & 3(2) & 14(2) & 1(2) \\ & 3097(2) & 3625(1) & 1312(2) & 36 & 25 & 63 & 1 & 12 & 0 \\ \mathrm{C}(5) & 3199(5) & 1197(4) & 1266(6) & 33(2) & 24(2) & 51(2) & -3(2) & 10(1) & 2(2) \\ & 3188(2) & 1198(2) & 1270(2) & 32 & 32 & 47 & -1 & 9 & 2 \\ \mathrm{C}(6) & 2404(5) & 45(4) & 1600(5) & 35(2) & 21(2) & 45(2) & -1(1) & 3(2) & 7(2) \\ & 2399(2) & 45(2) & 1603(2) & 37 & 26 & 46 & -1 & 6 & 3 \\ \mathrm{O}(W) & -3537(4) & 2933(3) & 258(5) & 37(2) & 41(2) & 56(2) & 3(1) & 11(1) & -1(1) \\ & -3534(2) & 2929(1) & 260(2) & 38 & 48 & 58 & 3 & 10 & 1\end{array}$


Table 2 (cont.)

(b) Hydrogen atoms. Final positional coordinates $\left(\times 10^{3}\right)$. $\mathrm{H}(W 1)$ and $\mathrm{H}(W 2)$ are the hydrogen atoms attached to the water oxygen $\mathrm{O}(W)$.

$\begin{array}{lrrr} & x & y & z \\ \mathrm{H}(1) & 24(5) & -61(4) & 233(5) \\ & 31(2) & -67(2) & 236(2) \\ \mathrm{H}(3) & 256(6) & 425(5) & 163(6) \\ & 259(3) & 434(2) & 157(2) \\ \mathrm{H}(4) & 411(6) & 353(4) & 78(6) \\ & 408(3) & 361(2) & 98(3) \\ \mathrm{H}(5) & 432(5) & 117(4) & 90(5) \\ & 420(3) & 122(2) & 87(3) \\ \mathrm{H}(6) & 291(5) & -86(4) & 151(5) \\ & 285(2) & -86(2) & 148(2) \\ \mathrm{H}(W 1) & -303(6) & 250(5) & 116(7) \\ & -294(3) & 250(2) & 105(3) \\ \mathrm{H}(W 2) & -287(7) & 313(5) & -38(7) \\ & -285(3) & 323(2) & -39(3)\end{array}$

\section{Structure refinement}

The starting-point for the refinement was the parameter set of MC. Full-matrix least-squares methods were employed with a set of programs written by Dr G. M. Sheldrick. Positional parameters for both nonhydrogen and $\mathrm{H}$ atoms were allowed to vary, as were the individual non-hydrogen anisotropic thermal parameters. The $\mathrm{H}$ isotropic thermal parameters were constrained to be the same as the atom to which each was bonded. This refinement scheme is essentially the same as that of $\mathrm{MC}$, and refinement converged satisfactorily (Table 1). Tables 2 and 3 list the final atomic parameters, and bond lengths and angles in both studies.*

\section{Results and discussion}

It is apparent that the structural parameters from the two analyses in general are in good agreement.

The method of normal probability plot analysis (Abrahams \& Keve, 1971) can be used to make more meaningful comparisons of two independent sets of measurements, by statistically analysing the standard deviations of the results. The method involves plotting the weighted differences $\delta m_{i}$ of pairs of results against their (tabulated) statistically expected values. $\delta m_{i}=$ $\left[P_{i}(1)-P_{i}(2)\right] /\left\{\sigma^{2}\left[P_{i}(1)\right]+\sigma^{2}\left[P_{i}(2)\right]\right\}^{1 / 2}$, where $P_{i}(1)$ and $P_{i}(2)$ are each the same independent measurement of, in this case, an ith structural parameter, and $\sigma\left[P_{i}(1)\right]$ and $\sigma\left[P_{i}(2)\right]$ are the associated standard deviations from the full covariance least-squares matrix. If the parameter errors are randomly normally distributed, the plots should be linear, with zero intercept and unit slope.

* A list of structure factors has been deposited with the British Library Lending Division as Supplementary Publication No. SUP 31618 (6 pp.). Copies may be obtained through The Executive Secretary, International Union of Crystallography, 13 White Friars, Chester CH1 1NZ, England.
Fig. 2(a) $-(c)$ shows the normal probability plots obtained for positional parameters, anisotropic thermal parameters, and bond lengths and angles;

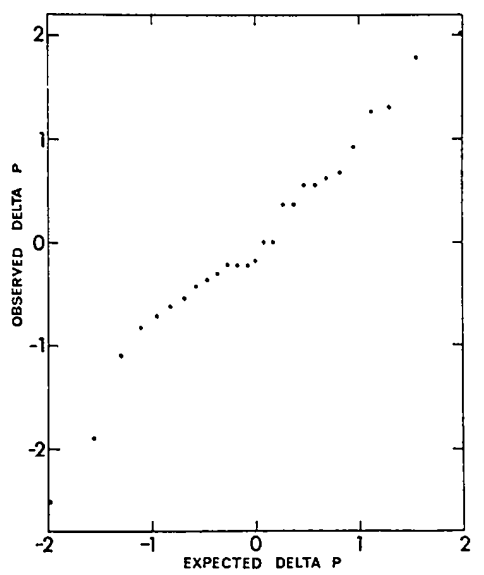

(a)

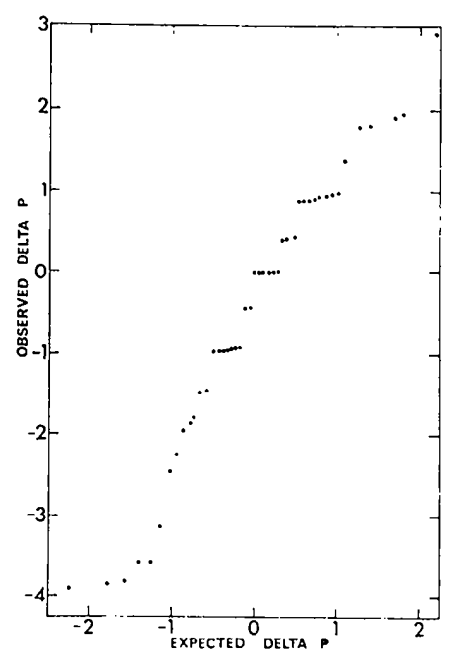

(b)

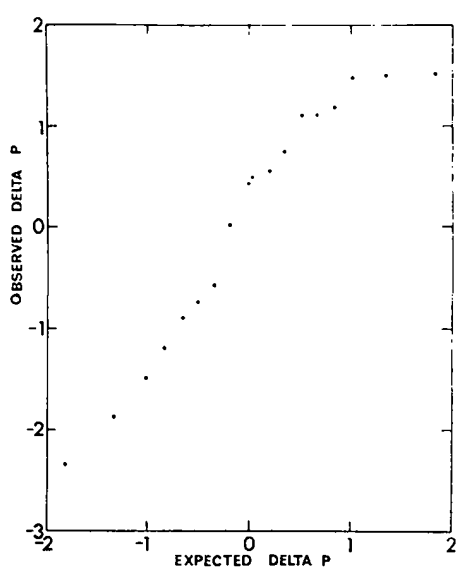

(c)

Fig. 2. Normal probability plots from (a) positional coordinates, $(b)$ vibrational parameters and $(c)$ bond lengths and angles. 
Table 3. Bond distances $(\AA)$ and angles $\left({ }^{\circ}\right)$, calculated from the positional parameters of Table 2

(a) Bond lengths

$\begin{array}{lcc} & \text { MC } & \begin{array}{c}\text { This analysis } \\ \sigma=0.004-0.005 \AA\end{array} \\ N(1)-C(2) & 1.371 & 1.376 \\ \mathrm{C}(2)-\mathrm{N}(3) & 1.350 & 1.357 \\ \mathrm{~N}(3)-\mathrm{C}(4) & 1.341 & 1.337 \\ \mathrm{C}(4)-\mathrm{C}(5) & 1.425 & 1.431 \\ \mathrm{C}(5)-\mathrm{C}(6) & 1.333 & 1.336 \\ \mathrm{C}(6)-\mathrm{N}(1) & 1.353 & 1.357 \\ \mathrm{C}(2)-\mathrm{O}(2) & 1.251 & 1.251 \\ \mathrm{C}(4)-\mathrm{N}(4) & 1.326 & 1.334\end{array}$

(b) Bond angles

\begin{tabular}{|c|c|c|}
\hline & $\begin{array}{c}\mathrm{MC} \\
\sigma=0.15^{\circ}\end{array}$ & $\begin{array}{l}\text { This analysis } \\
\sigma=0 \cdot 3-0 \cdot 4^{\circ}\end{array}$ \\
\hline$C(2)-N(1)-C(6)$ & $121 \cdot 5$ & $121 \cdot 2$ \\
\hline $\mathrm{N}(1)-\mathrm{C}(2)-\mathrm{N}(3)$ & $119 \cdot 6$ & $119 \cdot 7$ \\
\hline $\mathrm{C}(2)-\mathrm{N}(3)-\mathrm{C}(4)$ & $119 \cdot 1$ & $118 \cdot 7$ \\
\hline$N(3)-C(4)-C(5)$ & $121 \cdot 7$ & $122 \cdot 5$ \\
\hline$C(4)-C(5)-C(6)$ & $117 \cdot 5$ & $116 \cdot 7$ \\
\hline$C(5)-C(6)-N(1)$ & $120 \cdot 5$ & $121 \cdot 0$ \\
\hline $\mathrm{N}(1)-\mathrm{C}(2)-\mathrm{O}(2)$ & $118 \cdot 5$ & $118 \cdot 9$ \\
\hline$N(3)-C(4)-N(4)$ & $118 \cdot 1$ & $118 \cdot 2$ \\
\hline $\mathrm{C}(5)-\mathrm{C}(4)-\mathrm{N}(4)$ & $120 \cdot 2$ & $119 \cdot 2$ \\
\hline $\mathrm{N}(1)-\mathrm{C}(2)-\mathrm{O}(2)$ & $118 \cdot 5$ & 118.9 \\
\hline
\end{tabular}

in each case these are for the non-hydrogen atoms only, as the $\mathrm{H}$ atom positions are necessarily somewhat inaccurate [though Table $2(b)$ indicates a perhaps surprisingly good fit between the MC values and the photographic ones].

For each plot, a least-squares straight-line fit has been calculated. The correlation coefficient $r$ has also been calculated in order to test the linearity between the observed and expected $\delta P_{i}$ values; $r$ is defined as $M \sigma x / \sigma y$, where $M$ is the slope of the least-squares line, and $\sigma x$ and $\sigma y$ are the estimated standard deviations of expected and observed $\delta P_{i}$ values. An $r$ of unity indicates exact linearity, whereas an $r$ of zero means that the two sets of values are not linearly related at all.

Table 4 details the data obtained from the plots. For all three plots the correlation coefficient does not differ appreciably from unity, indicating random normal error statistics. The vibrational parameter plot has a significantly non-zero intercept, suggesting the presence of some systematic error in one or both sets of parameters. As Kratky \& Dunitz (1975) have pointed out, it is very difficult to decide which of the many possible sources of systematic error is a major contributor to the differences between the two sets of results; we have not attempted to do so. However, it may be significant that the $\mathrm{MC}$ data were not corrected for absorption effects. The 1.5 slope of Fig. $2(b)$ also indicates that the $U_{i j}$ standard deviations have been underestimated by a factor of 1.5 .

Examination of the slopes and intercepts from the least-squares straight lines of Fig. 2(a) and (c) indicates only minimal systematic error in the positional parameters. Furthermore the $>1$ slopes of both point to slight underestimation of the associated standard deviations.
Table 4. Various values obtained from the normal probability plots

\begin{tabular}{|c|c|c|c|c|}
\hline $\begin{array}{l}\text { Values } \\
\text { compared }\end{array}$ & $\begin{array}{l}\text { Range of } \\
\qquad \delta P\end{array}$ & Slope & Intercept & $\begin{array}{c}\text { Correlation } \\
\text { coefficient }\end{array}$ \\
\hline $\begin{array}{l}\text { Positional } \\
\text { parameters }\end{array}$ & $\begin{array}{c}+2.04 \text { to } \\
-2.52\end{array}$ & $1 \cdot 02$ & 0.00 & 0.98 \\
\hline $\begin{array}{l}\text { Vibrational } \\
\text { parameters }\end{array}$ & $\begin{array}{c}+2.94 \text { to } \\
-3.91\end{array}$ & $1 \cdot 76$ & -0.49 & 0.98 \\
\hline $\begin{array}{l}\text { Bond lengths } \\
\text { and angles }\end{array}$ & $\begin{array}{c}+1.56 \text { to } \\
-2.34\end{array}$ & $1 \cdot 25$ & 0.04 & 0.97 \\
\hline
\end{tabular}

\section{Conclusion}

It is clear that the structural parameters derived from the diffractometer, and the photographic intensities have a large measure of good agreement. This is particularly so for the positional parameters, and rather less so for the vibrational ones. (It is well known that the latter are more sensitive to systematic errors, especially those due to absorption effects.) Our study has therefore shown that especially for the former, the differences between the two structures are adequately described by their estimated standard deviations. It is thus apparent that digital scanning of Weissenberg films can produce structural information comparable to that obtained from diffractometric studies, at least for structure determinations of moderate accuracy. Our results also suggest that the procedure used by the Science Research Scanner Service, to process the digital information into integrated reflexion intensities, is an accurate one.

We are grateful to M. Elder and P. A. Machin, and their staff at the SRC Atlas Computer Laboratory, for their help and advice and for scanning the films. The Cancer Research Campaign and the Lawson Tait Trust are thanked for grant support.

\section{References}

Abrahams, S. C. \& Keve, E. T. (1971). Acta Cryst. A27, $157-165$.

Arndt, U. W., Champness, J. C., Phizackerley, R. P. \& Wonacott, A. J. (1973). J. Appl. Cryst. 6, 457-463.

Jefrerey, G. A. \& Kinoshita, Y. (1963). Acta Cryst. 16, 20-28.

Kratky, C. \& Dunitz, J. D. (1975). Acta Cryst. B31, $1586-1589$.

McCluRe, R. J. \& Craven, B. M. (1973). Acta Cryst. B29, $1234-1238$.

Machin, P. A. \& Elder, M. (1975). Science Research Council Microdensitometer Service Annual Report.

Matthews, B. W., Klopfenstein, C. E. \& Colman, P. M. (1972). J. Sci. Instrum. 5, 353-359.

Suölin, L., Olsson, G. \& LindQvist, O. (1975). J. Appl. Cryst. 8, 678-680.

Sussman, J. L. \& Wodak, S. J. (1973). Acta Cryst. B29, 2918-2926.

Werner, P. E., LinNRos, B. \& LeijonmarcK, M. (1971). Acta Chem. Scand. 25, 1297-1312.

XUONG, Ng. H. \& Freer, S. T. (1971). Acta Cryst. B27, 2380-2387. 